\title{
CLINICAL EFFICACY OF PYRIDOXINE AND MEFENAMIC ACID ALONE AND IN COMBINATION IN PREMENSTRUAL SYNDROME
}

\section{JAGMINDER KAUR BAJAJ1, SATINDER JIT SINGH², PREM PARKASH KHOSLA ${ }^{3}$ AND RANI WALIA4}

\author{
${ }^{1}$ Dept of Pharmacology, Punjab institute of Medical sciences, Jalandhar, Punjab, India. \\ ${ }^{2}$ Trauma Centre, Civil Hospital, Jalandhar, Punjab, India. \\ 3Dept of Pharmacology, Gian Sagar Medical College, Banur, Patiala, Punjab, India. \\ ${ }^{4}$ Dept of Pharmacology, Maullana Medical College, Ambala, Haryana, India. \\ *Corresponding Author: Email- jagminder1@rediffmail.com, pharmaco@pimsj.com
}

Received: December 12, 2011; Accepted: January 18, 2012

\begin{abstract}
A wide range of drugs from different pharmacological groups have been tried in premenstrual syndrome by various investigators, with contradictory reports. Pyridoxine is reported to relieve autonomic and behavioural symptoms and NSAIDs to relieve physical symptoms. The present study evaluated and compared with placebo, the clinical efficacy of Pyridoxine and Mefenamic acid alone \& in combination in relieving symptoms of pre-menstrual syndrome(PMS)

Material/ Methods- 80 female patients between 18- 45 years of age, diagnosed to be suffering from PMS were randomly divided into 4 groups (A,B,C,D) of 20 patients each. They received Placebo tablets, Pyridoxine $\mathrm{HCl} 100 \mathrm{mg} \mathrm{OD}$, Mefenamic acid $250 \mathrm{mg}$ TDS and a combination of Pyridoxine and Mefenamic acid respectively for 7 days preceeding menstruation. Patients filled 36 item PMTS self rating scale and 22 item daily diary for 2 months before treatment to record baseline symptoms and during treatment cycle. 22 symptoms were divided into 4 subsets of physical, anxiety related, depression related and fluid- electrolyte related symptoms to study effect of drugs.

Results- Statistically significant improvement from baseline symptoms occurred in patients receiving Pyridoxine, Mefenamic acid and their combination (group B,C, D), but mean \%age improvement in all the 3 groups was not significantly different from Placebo ( $p>0.05)$. Significant $(p<0.05)$ improvement in subset of physical symptoms occurred with mefenamic acid alone, but not with combination of pyridoxine and mefenamic acid.
\end{abstract}

Conclusion- Placebo controll group must always be included in Premensrual syndrome trials. Mefenamic acid 250 mg TDS for 7 days preceeding menses relieved physical symptoms of PMS. However the beneficial effect was lost on combining pyridoxine

Key words- Confusion matrix, Data Mining, Decision tree, Neural Network, stacking ensemble, voted perceptron

Citation: Jagminder Kaur Bajaj, et al. (2012) Clinical Efficacy of pyridoxine and mefenamic acid alone and in combination in Premenstrual syndrome. International Journal of Medical and Clinical Research (IJMCR), ISSN:0976-5530 \& E-ISSN:0976-5549, Volume 3, Issue 2, pp115-117.

Copyright: Copyright@2012 Jagminder Kaur Bajaj, et al. This is an open-access article distributed under the terms of the Creative Commons Attribution License, which permits unrestricted use, distribution, and reproduction in any medium, provided the original author and source are credited.

\section{Introduction}

PMS (Premenstrual syndrome) is a multifactorial, psycho neuroendocrine disorder, characterised by cyclical recurrence of a combination of various physical, psychological, affective, behavioural, cognitive, neuro-vegetative and autonomic symptoms, not caused by any organic disease, which regularly recur during luteal phase of menstrual cycle and regress during the proliferative phase. Symptoms of PMS are usually severe enough to interfere with normal activities, deteriorate interpersonal relationships, increase accident proneness and incidence of acts of violence. Numerous hypotheses have been advanced to explain varied premenstrual symptoms but a cohesive pathophysiological formulation is yet to be established. Altered estrogen to progesterone ratio, decreased whole blood serotonin levels, pyridoxine deficiency, hypoglycemia,prostaglandins and failure to maintain opioid tonus have been implicated from time to time in the causation of premenstrual symptoms. In the absence of a precise etiology, the various modalities of treatment including pyridoxine, NSAIDS and HRT are yet empirical. A wide range of drugs like hormonal preprations(progesterone, oral contraceptives), antihormonal preprations (danazol), psychotropic drugs (lithium, tricyclic antidepressants, sedative hypnotics, MAO inhibitors etc.), bromocryptine, diuretics, pyridoxine, prosta- 
glandin precursor inhibitors, NSAIDs had been tried in past by various investigators, in the treatment of PMS. Many trials have been done to study the possible role of vitamin B6 in PMS, but results are contradictory [1-4] It is reported to relieve autonomic and behavioural symptoms of PMS [5]. PG synthesis inhibitors (NSAIDs) are reported to relieve physical symptoms of PMS [6,7]. It is worthwhile to try a combination of pyridoxine $\mathrm{Hcl}$ and mefenamic acid in an attempt to alleviate the autonomic, behavioural and physical symptoms of PMS. Objective of the present study was to evaluate and compare with placebo, the clinical efficacy of pyridoxine, and mefenamic acid alone as well as in combination in patients suffering from PMS in a prospective, double blind, parallel group trial.

\section{Materials and Methods}

Study parameters were :

1. Preliminary survey list of 18 symptoms irritability, decreased concentration, anxiety/tension, aggression, depression, mood swings, emotional labiality, lethargy, restlessness, poor coordination, generalised swelling, swelling of hands/ feet, abdominal bloating, weight gain, headache, breast tenderness, cravings for sweet/salty food, change in bowel habits.

2. Steiner's PMTS self rating scale [8] of 36 questions to be answered as yes/ no

3. Samuel Smith's Daily diary of 22 symptoms with a scale of symptoms from 0-3 [9]

4. Subjects' global assessment of improvement 0 to +4 or worsening -1 to -4

5. Check list of side effects (diarrhoea, pain epigastrium, fever, skin rashes, jaundice, chest pain, pallor, splenomegaly

6. Any spontaneously reported side effects.

Patients attending the pre menstrual symptom clinic of Department of Obstetrics \& Gynaecology of Govt. Medical college \& Rajindra Hospital, Patiala were surveyed for 18 symptoms during later part of the menstrual cycle in any of the last 3 cycles. Those with 3 or more symptoms were verified for inclusion criteria (18-45 years old females, regular, normal menstrual cycles ranging 21- 35 days, married participants using no or barrier contraceptives) and ruled out for exclusion criteria

(any concurrent illness, pregnancy, lactation, alcohol or drug abuse, using hormonal contraceptives ). Selected patients filled PMTS self rating scale twice i.e. on day 26 \& on day 7-9 after menstruation and those with a score of $>18$ in luteal phase and $<6$ after onset of menstruation were enrolled after they signed an informed written consent.80 patients thus selected filed SamuelSmith's daily diary for 2 cycles without any treatment to record baseline symptoms. They were randomly divided into 4 groups $(n=20)$ using computer devised numbers. Group A received placebo, Group B Tab.pyridoxine HCl SR 100mg OD, Group C- Tab. Mefenamic acid 250mg TDS and Group D- combination of pyridoxine and mefenamic acid in same dose for 7 days before next expected period. All patients filled Samuel Smith's daily diary.for treatment cycle. Compliance was checked by tablet counting. Check list of side effects was filled. Any spontaneously reported side effects were recorded.

\section{Statistics}

Values were expressed as mean \pm S.E., median \& range. Fischer's exact probability test was used to compare patients' socio- demographic features, ANOVA to compare menstrual cycle characteristics and Mann-Whitney's $U$ test to compare the median symptom scores before \& after treatment, the mean \%age improvement of groups B, C \& D with placebo and effect of drugs on subsets of symptoms

\section{Results}

All the 4 groups were comparable in terms of age, occupation and socio-economic as shown in table 1 . The differences in mean \pm S.E were insignificant statistically $(p>0.05)$ by Fischer's probability test. [See Table 1]

The menstrual cycle characteristics of patients in 4 groups were also comparable as shown in table 2. [See Table 2]

Baseline median symptom of 4 groups was not significantly different from each other. The comparison of median symptom score before and after treatment revealed statistically significant improvement with pyridoxine $(p<0.02)$ and mefenamic acid alone $(p<$ 0.001 ) as well as in combination ( $p<0.05)$, but not with placebo

Table 3- Showing Median symptom score of 4 groups before and after treatment

\begin{tabular}{|llll} 
GROUP & $\begin{array}{l}\text { MEDIAN SYMPTOM } \\
\text { SCORE BEFORE- } \\
\text { TREATMENT }\end{array}$ & $\begin{array}{l}\text { MEDIAN SYMPTOM } \\
\text { SCORE AFTER }\end{array}$ & $\begin{array}{l}\text { Mann Whit- } \\
\text { TREATMENT U test } p\end{array}$ \\
A & 74.25 & 47.16 & \\
B & 74.9 & 41.06 & $>0.05$ \\
C & 79.5 & 38.2 & $<0.02$ \\
D & 79.83 & 49.3 & $<0.001$ \\
& $\begin{array}{ll}\text { P }>0.8 \text { ( Kruskalwall's } \\
\text { analysis of varience) }\end{array}$ & \\
\multicolumn{2}{l}{} \\
\hline
\end{tabular}

However none of the treatments given was significantly better than placebo in mean \%age improvement ( table $4 p>0.05$ ). This emphasizes the importance of including placebo control group in the trials of premenstrual syndrome.

Table 4- Comparing mean \%age improvement of group B, C\& D with group A i.e. $34.33 \%$

\begin{tabular}{lll} 
GROUP & MEAN \%AGE IMPROVEMENT & Mann Whitney U test $p$ \\
GROUP B & 38.95 & $>0.05$ \\
GROUP C & 46.65 & $>0.05$ \\
GROUP D & 32.18 & $>0.05$ \\
\hline
\end{tabular}

Comparison of placebo group with other 3 groups in improvement / deterioration of various subset of symptoms in table 5 showed statistically significant improvement only in physical symptoms with mefenamic acid alone $(p<0.05)$. However this beneficial effect was lost on combining pyridoxine with mefenamic acid pointing towards the possibility of some adverse interaction between the two drugs.

Table 5- Statistical comparison of group A with other 3 groups on subset of symptoms

\begin{tabular}{|llll|} 
SUBSET OF SYMPTOMS & \multicolumn{2}{c}{ GP A vs GP B GP A vs GP C GP A vs GP D } \\
PHYSICAL & $U-155.5$ & $U-111.5$ & $U-159.5$ \\
& $p>0.05$ & $p<0.05^{*}$ & $p>0.05$ \\
ANXIETY RELATED & $U 164$ & $U-170$ & $U-183$ \\
& $p>0.05$ & $p>0.05$ & $p>0.05$ \\
DEPRESSION RELATED & $U-149.5$ & $U 150$ & $U-152$ \\
& $p>0.05$ & $p>0.05$ & $p>0.05$ \\
FLUID/ ELECTROLYTE RELATED & $U-128.5$ & $U-117.5$ & $U-143$ \\
& $p>0.05$ & $p>0.05$ & $p>0.05$ \\
\hline
\end{tabular}




\section{Conclusions}

- The most important conclusion drawn from our study is that clinical trials of various groups of drugs in PMS must always be placebo controlled, because although statistically significant improvement in median symptom score occurred with pyridoxine, mefenamic acid and their combination but overall clinical response in the form of mean \%age improvement in these 3 groups was not significantly different from placebo.

- Mefenamic acid relieves physical symptoms of PMS. But response to pyridoxine alone and conmbination of pyridoxine and mefenamic acid was similar to placebo

- There is no significant difference between 4 groups on anxiety related, depression related \& fluid electrolyte related symptoms.

\section{Discussion}

There was significant improvement in median symptom score from baseline symptoms with pyridoxine, mefenamic acid alone and their combination , but the mean \%age improvement in PMS symptoms was not significantly different from placebo in any group. Thus it is stressed that all clinical trials of PMS should be placebo controlled. In our study with mefenamic acid alone, improvement in subset of physical symptoms was significantly better than placebo $(p<0.05)$. This is in aggrement with results of Michael Mira etal 1986 [10] . On administering pyridoxine alone or in combination with mefenamic acid there was no significant improvement in physical symptoms. This might be because of subjective symptoms caused as a side effect of high doses of pyridoxine. The possiility of any drug interaction between pyridoxine and mefenamic acid needs further studies. Further the mean \%age improvement caused by pyridoxine was no better than placebo $(p>0.05)$ These findings are in aggrement with the results of 2 double blind, placebo controlled studies by stokes etal 1972 [1] and Hagen etal 1985 [2] . But our results are contradictory to Abraham etal 1980[3] who favoured use of pyridoxine in premenstrual syndrome. The differences might be due to higher doses $(500 \mathrm{mg}$ ) and longer duration of treatment (3 months) with pyridoxine in Abraham's study. Whereas in our study, dose of pyridoxine was $100 \mathrm{mg}$ and duration of treatment was 7 days for ethical reasons as Schaumberg,H. Etal 1983[11] and Pary, G.I. Etal 1985 [12] had reported sensory neuropathy with long term use of even low doses of pyridoxine. Susan,
R.J 1992 [13] had recommended that dose of pyridoxine should not exceeed $100 \mathrm{mg}$. Our results are also in disaggrement with Hamilton etal 1984 [14] and bancroft etal 1985 [15] . But these studies were not controlled studies. In an uncontrolled study it is not possible to find out whether any change or improvement could have occurred, had the patient been given a placebo rather than the active drug.

Strength of the study lies in prospective diagnosis, placebo control, large sample size (80 patients), double blinding, randomisation sand study of effects of drugs on subsets of symptoms. An important limitation of the present study was parallel group design (which was selected to reduce the duration of trial, to improve patient compliance and reduce drop out rates) Secondly procedure of trial was such that could be followed only by educated subjects . So patients below 5 th standard of education could not be included in the study.

\section{References}

[1] Stokes J.W., Mendels J. (1972) Lancet ,1,1177.

[2] Hagen I., Nesheim B., Tuntland T. (1985) Acta Obstet Gynecol Scand, 64,667.

[3] Abraham G.E., Hargrove J.T. (1980) Infert, 3, 155-165.

[4] Mattes J.A., Martin D. (1983) Hum Nutr Appl Nutr 36, 131.

[5] Kendall K.E., Schnurr P.P. (1987) Obstet Gynecol 70, 145.

[6] Facchinetti F., Fioroni L., Sances G., Romano G., Nappi G., Genazzani A.R. (1989) Gynecol Obstet Invest 28, 205-208.

[7] Jakubowicz D.L., Goddard E., Dewhurst J. (1984) Br J obstet Gynecol 91, 78.

[8] Steiner M., Haskett R.F., Carroll B.J. (1980) Acta psychiatr Scand 62,177 - 191.

[9] Smith S., Rinehart J.S., Ruddock V.E., Schiff I. (1987) Obstet Gynecol, 70, 37.

[10]Michael M., Don M., Fraser I.S., Vizzard J., Abraham S. (1986) Obstet Gynecol, 68 , 395.

[11]Schaumberg H., Kaplan J., Windebank A. etal (1983) N Eng J Med 309, 445.

[12]Pary G.I., Bredson D.E. (1985) Neurology $35,1466$.

[13]Susan R.J. (1992) Clinical Obstet and Gynecol, 3, 35, 637.

[14]Hamilton J.A., Gallant S. (1988) Psychoneuroendocrinol, 13, 505.

[15]Bancroft J., Backstrom T. (1985) clin endocrinol, 22, 313.

Table 1 - Socio-demographic features of patients

\begin{tabular}{|lllllll|} 
FEATURE & & GROUP A & GROUP B & GROUP C & GROUP D & $p$ \\
\multirow{4}{*}{ AGE } & MEAN+/-S.E. & $22.8+0.79$ & 22.70 .84 & 21.30 .83 & 23.51 .73 & $>0.05$ \\
& RANGE (YEARS) & $18-30$ & $19-36$ & $18-34$ & $18-42$ & \\
& $5^{\text {th }}-10^{\text {th }}$ & 1 & 1 & 1 & 3 & \\
EDUCATION & $>10^{\text {th }}$ & 2 & 1 & 1 & 2 & \\
& PROFESSIONALS & 17 & 18 & 18 & 15 & $>0.05$ \\
OCCUPATION & HOUSE-WIVES & 2 & 1 & 4 & 5 & $>0.05$ \\
& WORKING & 18 & 19 & 16 & 15 & \\
SOCIO-ECONOMIC & UPPER & 2 & 1 & 0 & 0 & \\
STATUS & MIDDLE & 17 & 18 & 19 & 18 & \\
\hline
\end{tabular}

Table 2 Showing Comparison of Menstrual cycle characteristics

\begin{tabular}{|c|c|c|c|c|c|c|}
\hline PARAMETER & & GROUP A & GROUP B & GROUP C & GROUP D & p \\
\hline $\begin{array}{l}\text { DURATION (IN DAYS) } \\
\text { CYCLE LENGTH ( IN DAYS) }\end{array}$ & MEAN S.E. & $\begin{array}{l}4.05033 \\
29.4\end{array}$ & $\begin{array}{l}4.2037 \\
28.55\end{array}$ & $\begin{array}{l}4.10 .24 \\
27.54\end{array}$ & $\begin{array}{l}4.450 .19 \\
26 . .85\end{array}$ & $\begin{array}{l}>0.05 \\
>0.05\end{array}$ \\
\hline
\end{tabular}

